\title{
Maternal autonomy and high-risk pregnancy in Bangladesh: the mediating influences of childbearing practices and antenatal care
}

\author{
Sumaiya Abedin ${ }^{1 *}$ and Dharma Arunachalam²
}

\begin{abstract}
Background: Maternal, infant and neonatal mortality rates are high in Bangladesh. Certain childbearing practices and poor utilisation of antenatal care services make Bangladeshi women more vulnerable to experience poor health during pregnancy and adverse pregnancy outcomes. Also, women in Bangladesh remain considerably subordinate to men in almost all aspects of their lives, from education and work opportunities to healthcare utilisation. This study investigates the severity of health complications during pregnancy in relation to women's autonomy, and how childbearing practices and utilisation of antenatal care mediate this relationship.

Methods: Data from the most recent Bangladesh Demographic and Health Survey (BDHS) is used in this study. Multinomial regression models (MLRM) are employed to examine the relationship between the outcome variable high risk pregnancy, and explanatory variables - women's autonomy, childbearing practices and use of antenatal care.

Results: In Bangladesh, about 41.5\% of women experienced high-risk pregnancies involving multiple health complications. Findings showed that women's autonomy in decision-making, freedom of movement and economic autonomy were significantly associated with high-risk pregnancies. However, women's autonomy in physical mobility in particular did so only through the mediating factors of maternal childbearing practices and antenatal care. Specifically, both early and delayed childbearing and shorter birth interval increased the likelihood of high-risk (multiple complications) pregnancies by about 30\% and 31\% respectively, high parity increased the risk by 23\% and use of antenatal care decreased it by $46 \%$.

Conclusions: The Women's decision-making autonomy, freedom of movement and economic autonomy had significant effects on high-risk pregnancies. However, the effects were mediated by both maternal childbearing practices and use of antenatal care in a limited way. Policies and programmes aimed at improving pregnancy outcomes need to focus on all three sets of factors: women's autonomy, childbearing practices and use of antenatal care.
\end{abstract}

Keywords: Autonomy, Antenatal care, Childbearing practices, High-risk pregnancy, Mediating effect

\footnotetext{
* Correspondence: su.abedin@gmail.com

'Department of Population Science, University of Rajshahi, Rajshahi, Bangladesh

Full list of author information is available at the end of the article
}

(c) The Author(s). 2020 Open Access This article is licensed under a Creative Commons Attribution 4.0 International License, which permits use, sharing, adaptation, distribution and reproduction in any medium or format, as long as you give appropriate credit to the original author(s) and the source, provide a link to the Creative Commons licence, and indicate if changes were made. The images or other third party material in this article are included in the article's Creative Commons licence, unless indicated otherwise in a credit line to the material. If material is not included in the article's Creative Commons licence and your intended use is not permitted by statutory regulation or exceeds the permitted use, you will need to obtain permission directly from the copyright holder. To view a copy of this licence, visit http://creativecommons.org/licenses/by/4.0/. The Creative Commons Public Domain Dedication waiver (http://creativecommons.org/publicdomain/zero/1.0/) applies to the data made available in this article, unless otherwise stated in a credit line to the data. 


\section{Background}

Maternal and perinatal deaths as well as poor pregnancy outcomes is recognised as one of the major public health problems in Bangladesh. The common immediate causes of adverse pregnancy outcomes are mainly understood in terms of women's physiological health during pregnancy and childbirth. Although pregnancy is a universal part of female physiology and biology, this event is shaped by the surrounding social environment [1]. A pregnancy becomes high-risk when either the mother or the newborn (or both) have a significant risk of morbidity or mortality $[2,3]$. Studies on pregnancy health and childbirth are mainly concerned with physiological aspects, and only pay limited attention to maternal fertility behaviour, healthcare practices, and women's socioeconomic background. This study extends this knowledge by examining the relationship between maternal autonomy and the severity of pregnancy health complications followed by high-risk pregnancies among Bangladeshi women.

As highlighted in previous studies, women with low levels of education, low income and living in rural areas tend to enjoy low level of autonomy in reproductive health matters which increase the risk of poor pregnancy outcomes [4-9]. The identified risk factors for developing pregnancy complications were also found to be associated with certain childbearing practices which contribute to poor outcomes. A large number of studies have identified the adverse effects of adolescent pregnancies which increased the chance of experiencing several health complications during pregnancy: anaemia, hypertension or preeclampsia, gestational diabetes, placental problems, preterm labour and postpartum haemorrhage [10-14]. In Bangladesh, most studies arrived at similar conclusions: adolescent pregnancies hold an increased risk of pregnancy and delivery complications [15-17].

Also, women who had given birth to a large number of children (more than three births) and had them in shorter birth intervals of less than 18 months were found to be more vulnerable to experience several pregnancy complications: pre-eclampsia, pregnancy infections, miscarriage, stillbirth and low birth weight [16, 18-22]. Additionally, access to reproductive healthcare services remained a key determinant of a sound pregnancy and healthy outcome $[17,23]$. In this context, a large number of studies from developing countries including Bangladesh identified women's autonomy as a significant factor in the utilisation of antenatal care services [9, 24-27]. Although the associations between pregnancy health status, and maternal childbearing practices as well utilization of maternal healthcare have been widely recognized, the association between maternal autonomy and pregnancy health complications followed by high-risk pregnancies has not yet received similar attention. This study therefore investigates the association between women's autonomy and high-risk pregnancies, and also examines the mediating role of women's childbearing practices and antenatal care utilization in this relationship. The assumed key relations between autonomy and high-risk pregnancies through the pathways of maternal childbearing practices and antenatal care are shown in the diagram in Fig. 1.

\section{Data and methodology}

The present study is based on data from the Verbal Autopsy Questionnaire of Bangladesh Demographic and Health Survey 2011 (BDHS), which was the most recent survey that used the WHO Verbal Autopsy Questionnaire. Through this questionnaire, information on several health complications during pregnancy and delivery was collected from ever-married women aged 10-49 years for their most recent pregnancy in the five years preceding the survey. In the BDHS, the participants were recruited using a two-stage stratified cluster sample of households yielding a response rate of $98 \%$. Details of data collection and management procedures are described elsewhere in 2011 BDHS [28]. The analysis reported here is based on a sample of 327 women for whom information was available for all the variables used in this paper.

\section{Outcome variable}

Any health complication during pregnancy can decipher some degrees of risk, and a number of health complications may decipher higher degrees of risk. A number of complications that a woman may experience during pregnancy are combined by forming a single measure to derive the outcome variable high-risk-pregnancy. A score of ' 0 ' or ' 1 ' is assigned for a complication given that the complication is not experienced or experienced, respectively by a woman during the pregnancy. Scores were assigned to a number of health complications: blunted vision, convulsion, excessive bleeding during labour, gestational diabetes, heart disease, high blood pressure, high fever, long labour, puffy face, severe headache, shortness of breath, and vaginal bleeding. A measure of pregnancy risk is formed by adding scores of all pregnancy complications and this measure ranges from 0 (no complication during pregnancy) to 12 (experiencing all the complications during pregnancy). Based on the univariate distribution of this variable, this variable was collapsed, for analytical purposes, into a three-category outcome variable: no risk (no complication), low risk (one-two complications), and high risk (three or more complications).

\section{Predictor and mediating variables}

The primary predictor variable in this study is comprised of three autonomy variables: decision-making autonomy (assessed through questions relating to decisions about 


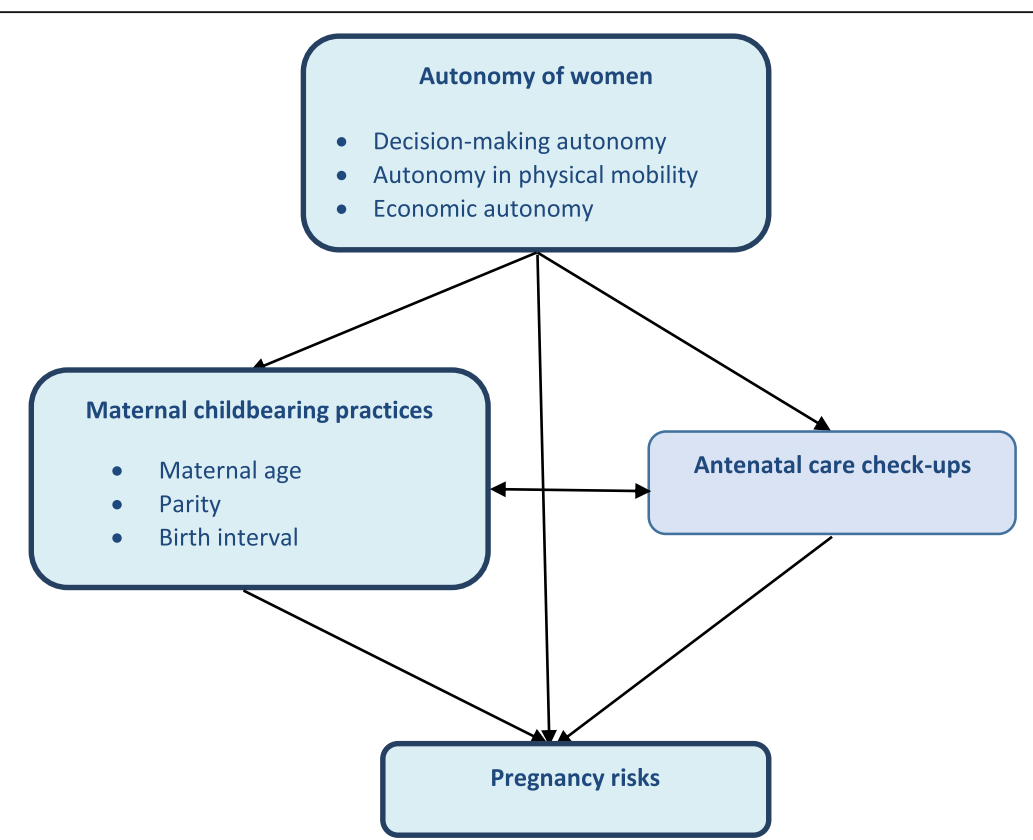

Fig. 1 Relationship between autonomy and high-risk pregnancies through the pathways of childbearing practices and antenatal care

household purchases, about their own healthcare, their children's healthcare, contraception, and the number and timing of births), autonomy in physical mobility or freedom of movement (assessed through questions related to the ability of women to visit friends and family, and access to healthcare services without any restriction), and economic autonomy (assessed through the ability to spend money when necessary, including for healthcare purposes). Responses to all the items were combined to produce a total score for each type of autonomy. Each total score was then collapsed into three categories: no autonomy (respondent can't decide at all, either husband or other family member decides about their lives); partial autonomy (respondent has the ability of make joint decisions with husband or other family members); and high autonomy (respondent has the ability to make the decision on their own). As there were relatively few women who reported 'partial autonomy', we combined the 'partial' and 'high' into a single 'autonomous' category.

In this study, maternal childbearing practices and uptake of antenatal care services were hypothesized to mediate the associations between maternal autonomy and levels of pregnancy risk. Childbearing practices included three variables: timing of the recent birth (low risk: ontime childbearing, 20 to 34 years; and high risk: early or delayed childbearing, below 20 years or above 34 years), parity (low-risk: 1-3 births; and high-risk: more than three births) and birth interval (low-risk: 18 months and more; and high-risk: less than 18 months). Antenatal care uptake was categorised as: women had insufficient antenatal care (0-2 visits) and had sufficient antenatal care (at least three visits as recommended by the WHO).

\section{Statistical analysis}

The responses obtained from the study population were analysed using descriptive statistics and cross-tabulations. To investigate the influences of maternal autonomy on high-risk pregnancy multinomial logistic regression models (MLRM) were fitted to the categorical response variable -pregnancy risk, and the odds of low (one or two complications) and high (three or more complications) risks versus no risk were estimated. We fitted two regression models to the data. First, high-risk pregnancy of women is examined with only autonomy variables included in the model, and then the variables maternal childbearing practices and antenatal care were added to the model to assess their roles in influencing the relationship between autonomy and highrisk pregnancy.

\section{Findings of the study \\ Prevalence of pregnancy complications}

Table 1 presents information about the most recent live births for which mothers experienced any pregnancy complication. This table shows that over one in ten women (11.5\%) had pregnancy-related diabetics. About $9.1 \%$ and $6.1 \%$ women (i.e. about one in seven women) had experienced two major complications (high blood pressure and convulsion, respectively) that were lifethreatening for both the mother and newborn. A significant proportion of women experienced some minor health complications during their pregnancy such as 
Table 1 Distribution of health complications during pregnancy among Bangladesh women, BDHS $2011(n=327)$

\begin{tabular}{lc}
\hline Pregnancy complications & Percentage of women \\
\hline High blood pressure & 9.1 \\
Gestational diabetes & 11.5 \\
Heart disease & 4.6 \\
Convulsion & 6.1 \\
Vaginal discharge & 4.5 \\
Puffy face & 17.0 \\
Blurred vision & 30.3 \\
Severe headache & 36.7 \\
High fever & 37.1 \\
Long labour & 28.8 \\
Excessive bleeding & 19.3 \\
Shortness of breath & 21.2 \\
Pregnancy risk & \\
No risk: No complication & 19.9 \\
Low risk: One to Two complications & 38.6 \\
High risk: More than two complications & 41.5 \\
All & 100.0 \\
\hline
\end{tabular}

blurred vision (30.3\%), severe headache (36.7\%), shortness of breath (21.2\%) and puffy face (17\%). About $28.8 \%$ of women had experienced labour lasting more than 12 hours, whereas about 19\% women experienced excessive bleeding during labour. When all the complications were combined, it is clear that the vast majority (80\%) had experienced at least one complication during pregnancy and childbirth. While about $38.6 \%$ of women had experienced one or two complications during pregnancy (low risk), a similar percentage $(41.5 \%)$ of women were reported to have experienced at least three health complications during pregnancy (high risk).

Table 2 provides information on the three components of autonomy and the four factors, namely maternal age, parity, birth interval and use of antenatal care, that were hypothesised to mediate the relationship between women's autonomy and the experience of high-risk pregnancy. It is interesting that most Bangladeshi women tended to enjoy at least some degree of autonomy in decision making (61.5\%) and freedom of mobility (54.5\%). But they seem to enjoy very little economic autonomy: about $86 \%$ of women included in the study did not report any degree of autonomy in economic matters. In terms of the mediating factors, the vast majority had their recent birth at the appropriate age (neither early, nor late), have had fewer than four births, and the average interval between births was at least 18 months. Table 2 further shows that one half of the women did not receive sufficient antenatal care.
Table 2 Women's autonomy, maternal childbearing practices and antenatal care among Bangladeshi women, BDHS 2011 $(n=327)$

\begin{tabular}{ll}
\hline Autonomy and mediating factors & Percentage of women \\
\hline Autonomy of women & \\
Decision-making autonomy & 38.5 \\
No autonomy & 61.5 \\
Autonomous & \\
Autonomy in physical mobility & 45.6 \\
No autonomy & 54.4 \\
Autonomous & \\
Economic autonomy & 86.2 \\
No autonomy & 13.8 \\
Autonomous & \\
Maternal childbearing practices & \\
Maternal age & 65.5 \\
Low-risk (20 to 34 years) & 34.5 \\
High-risk (<20 years and/or $>34$ years) & \\
Parity & \\
Low-risk (1-3 births) & 75.8 \\
High-risk ( $>3$ births) & 24.2 \\
Birth interval & \\
Low-risk ( $>18$ months) & \\
High-risk (<18 months) & \\
Antenatal care visits & \\
No sufficient ( $<3$ ANC visits) & \\
\hline
\end{tabular}

High-risk pregnancy and associated factors

We first examine the relationship between women's autonomy, mediating factors and high-risk pregnancy through conventional cross-tabulations. We then present the results from the regression analysis. Percentage distribution in Table 3 shows that, of the three dimensions of autonomy, only economic autonomy (ability to spend money when necessary) had a clear association with pregnancy risk although it was not statistically significant $(p=0.11)$. Among those who had the ability to decide on using the available economic resources (e.g. for health care), only $33 \%$ reported having experienced multiple complications during their last pregnancy compared to 50\% among those who reported that they did not enjoy any autonomy in economic matters. The association was weak (chi-square $=4.36, p=0.11$ ) which may be related to the fact that there was only a relatively small number of respondents who had reported some level of economic autonomy (13.8\%).

In contrast to autonomy variables, all the mediating variables had a strong and statistically significant relationship with pregnancy risks. Early or late childbearing, 
Table 3 Percentage distribution of women by pregnancy risk, and women's autonomy, maternal childbearing practices and antenatal care of Bangladesh women $(n=327)$

\begin{tabular}{|c|c|c|c|c|}
\hline \multirow[t]{2}{*}{ Characteristics of respondents } & \multicolumn{4}{|c|}{ Pregnancy risk (\%) } \\
\hline & No risk & Low risk & High risk & $\begin{array}{l}\text { Chi square } \\
\text { ( } p \text {-value) }\end{array}$ \\
\hline \multicolumn{5}{|l|}{ Autonomy of women } \\
\hline Decision-making autonomy & & & & \multirow[t]{3}{*}{$2.874(0.238)$} \\
\hline No autonomy & 20.6 & 29.4 & 50.0 & \\
\hline Autonomous & 19.4 & 34.3 & 46.3 & \\
\hline \multicolumn{4}{|l|}{ Autonomy in physical mobility } & \multirow[t]{3}{*}{$4.920(0.085)$} \\
\hline No autonomy & 24.8 & 28.2 & 47.0 & \\
\hline Autonomous & 15.7 & 36.0 & 48.3 & \\
\hline \multicolumn{4}{|l|}{ Economic autonomy } & \multirow{3}{*}{$\begin{array}{l}4.355 \\
(0.113)\end{array}$} \\
\hline No autonomy & 19.1 & 30.9 & 50.0 & \\
\hline Autonomous & 24.4 & 42.2 & 33.4 & \\
\hline \multicolumn{5}{|l|}{ Maternal childbearing practices } \\
\hline \multicolumn{4}{|l|}{ Maternal age } & \multirow{3}{*}{$\begin{array}{l}12.463 \\
(\mathbf{0 . 0 0 2})\end{array}$} \\
\hline Low-risk (20-34 years) & 20.9 & 32.0 & 47.1 & \\
\hline High-risk (<20 years and/or > 34 years) & 17.6 & 33.7 & 49.0 & \\
\hline \multicolumn{4}{|l|}{ Parity } & \multirow{3}{*}{$\begin{array}{l}8.864 \\
(\mathbf{0 . 0 1 1 )}\end{array}$} \\
\hline Low-risk (1-3 births) & 21.8 & 32.7 & 45.5 & \\
\hline High-risk (> 3 births) & 14.0 & 31.6 & 54.4 & \\
\hline \multicolumn{4}{|l|}{ Birth interval } & \multirow{3}{*}{$\begin{array}{l}9.034 \\
(\mathbf{0 . 0 1 2 )}\end{array}$} \\
\hline Low-risk (> 18 months) & 18.5 & 30.5 & 51.0 & \\
\hline High-risk (<18 months) & 21.6 & 36.2 & 42.2 & \\
\hline \multicolumn{5}{|l|}{ Antenatal care } \\
\hline No sufficient (<3 ANC visits) & 18.4 & 23.9 & 57.7 & \multirow[t]{2}{*}{$\begin{array}{l}14.342 \\
\mathbf{( 0 . 0 0 1 )}\end{array}$} \\
\hline Sufficient ( $\geq 3$ ANC visits) & 21.3 & 40.9 & 37.8 & \\
\hline
\end{tabular}

Low risk: One-Two pregnancy complications

High-risk: More than two pregnancy complications

higher parity and shorter birth intervals increased the risk of experiencing multiple complications (high risk) during pregnancy (Table 3). On the other hand, as would be expected, sufficient utilisation of antenatal health services, decreased the risk of multiple complications.

The estimated odds ratios (OR) from two regression models are presented in Table 4. Model 1 included only the autonomy variables and Model 2 includes both autonomy and mediating variables. In model 1 , all three autonomy variables had a strong $(\mathrm{OR}=0.63$ for economic autonomy) to moderately strong $(\mathrm{OR}=0.79$ for decision making) association with high risk (multiple complications) pregnancy. When the mediating variables were added in Model 2, women's autonomy in physical mobility was no more important. This shows that the influence of only one of the three autonomy variables seems to be mediated by factors related to childbearing and the use of antenatal care. However, all mediating variable were still important. Early and late age at childbirth increased the odds of high risk pregnancies by $30 \%$, shorter birth interval and higher parity increased it by $31 \%$ and $23 \%$ respectively, and sufficient uptake of antenatal care services decreased the odds by almost $46 \%$. The results confirmed that all but one autonomy variable had an independent effect on pregnancy risks, and that pregnancy risks are an outcome of the combined influences of respondents' childbearing practices, use of antenatal care and women's autonomy in decision making and economic autonomy. The role of women's autonomy in pregnancy complications was mediated only in a limited way by childbearing factors and use of antenatal care.

\section{Discussion}

Pregnancy is a complex and long-term biological transition in a woman's life with many associated health complications. Most pregnancies that result in natural vaginal births involve minor complications, such as 
Table 4 Estimated odds ratios (multinomial logistic regression models) of the effects of women's autonomy, maternal childbearing practices, and antenatal care on pregnancy risk of Bangladesh women

\begin{tabular}{|c|c|c|c|c|}
\hline \multirow[t]{2}{*}{ Variables } & \multicolumn{2}{|l|}{ Model 1} & \multicolumn{2}{|l|}{ Model 2} \\
\hline & $\begin{array}{l}\text { Low-risk } \\
\text { vs. } \\
\text { No risk }\end{array}$ & $\begin{array}{l}\text { High-risk } \\
\text { vs. } \\
\text { No risk }\end{array}$ & $\begin{array}{l}\text { Low-risk } \\
\text { vs. } \\
\text { No risk }\end{array}$ & $\begin{array}{l}\text { High-risk } \\
\text { vs. } \\
\text { No risk }\end{array}$ \\
\hline \multicolumn{5}{|l|}{$\begin{array}{l}\text { Autonomy of women } \\
\text { Decision-making autonomy }\end{array}$} \\
\hline No autonomy@ & - & - & - & - \\
\hline Autonomous & 0.82 & $0.79^{*}$ & 0.85 & $0.81^{*}$ \\
\hline \multicolumn{5}{|l|}{ Autonomy in physical mobility } \\
\hline No autonomy@ & - & - & - & - \\
\hline Autonomous & $0.86^{*}$ & $0.78^{*}$ & 0.71 & 1.08 \\
\hline \multicolumn{5}{|l|}{ Economic autonomy } \\
\hline No autonomy@ & - & - & - & - \\
\hline Autonomous & 0.55 & $0.63^{*}$ & 0.53 & $0.49^{*}$ \\
\hline \multicolumn{5}{|c|}{ Maternal childbearing practicesMaternal age } \\
\hline Low-risk (20-34 years)@ & & & - & - \\
\hline High-risk (<20 and/or > 34 years) & & & $1.21^{*}$ & $1.30^{*}$ \\
\hline \multicolumn{5}{|l|}{ Parity } \\
\hline Low-risk (1-3 births)@ & & & - & - \\
\hline High-risk (> 3 births) & & & $1.24^{*}$ & $1.23^{*}$ \\
\hline \multicolumn{5}{|l|}{ Birth interval } \\
\hline Low-risk (> 18 months)@ & & & - & - \\
\hline High-risk (< 18 months) & & & $1.23^{*}$ & $1.31^{*}$ \\
\hline \multicolumn{5}{|l|}{ Antenatal care } \\
\hline Insufficient (<3 ANC visits)@ & & & - & - \\
\hline Sufficient ( $\geq 3$ ANC visits) & & & $0.68^{*}$ & $0.54^{*}$ \\
\hline
\end{tabular}

nausea and vomiting, headache, blurred vision, puffy face or shortness of breath. On the other hand, major health problems during pregnancy include high blood pressure, convulsion, gestational diabetes, or pregnancy infections. When women experience several of these complications, they are deemed to be carrying a high-risk pregnancy, which contribute to poor outcomes for mother and baby, requiring special medical attention. However, the concept of high-risk pregnancy has not received the same level of attention in the literature as childbearing in general. The present study therefore examined high-risk pregnancies in Bangladesh from a socio-demographic viewpoint.

This study specifies an entrenched pattern of high-risk pregnancies in Bangladesh. The results of the present study identified a significant proportion of women in Bangladesh have experienced a number of health complications during pregnancy. Also, a significant number of women had multiple complications that contributed to an increased chance of pregnancy risks, either low or high. The findings on the relationship between women's autonomy, childbearing practices and pregnancy risks illustrate that all three dimensions of women's autonomy, when no other variables were included in the analysis (Table 4, Model 1), had significant influences on high-risk pregnancies. Earlier studies identified some indirect influences of autonomy indicators on pregnancy health status. It was found that freedom to go outside the home for healthcare purposes resulted in better maternal outcomes $[9,26,29]$. Independence in mobility can enable women to gather relevant information about pregnancy health, complications and remedy measures, thus contributed to healthy outcomes. In addition, high level of decision-making power about contraception, having children at a favourable time, spacing and number of children, as well as decision about own and child's healthcare also contributed to better pregnancy outcomes. In this context, decision-making autonomy, women's freedom of movement and ability to spend money when necessary to access maternal healthcare facilities reduce the prevalence of several health complications during pregnancy by ensuring higher levels of antenatal care utilization, which in turn decreases the 
chances of high-risk pregnancy. In this way, all three dimensions of maternal autonomy were found to be associated with sound pregnancy health.

This study explores that the high-risk pregnancy is strongly affected by childbearing practices and the use of antenatal care services. Akin to other developing countries, adolescent pregnancy is prevalent in Bangladesh and is subject to experience more complications. Our study demonstrates that the teenage and late pregnancies are more likely to possess several life-threatening complications. Teenage mothers are more likely to be less educated and less autonomous, and are lacking in awareness and experience regarding the danger signs of pregnancy complications. Thus they are less likely to receive proper prenatal and antenatal care to safeguard themselves from life-threatening complications. At the same time, some health complications during teenage pregnancy are triggered because of the biological effects of early childbearing. This phenomenon has also been focused in some earlier studies [14-16, 30-32]. Our study mimics the exposition of previous research that caesarean deliveries, preterm birth and stillbirths are likely to be more prevalent for grand multiparous (more than three children) women [19, 33]. Our empirical study demonstrates that high-risk birth interval, high birth order, and adolescent or delayed childbearing increase the risk of multiple complications during pregnancy which in turn leads to high-risk pregnancy outcomes.

Earlier studies investigated the adverse effects of short birth intervals on pregnancy health [20, 28, 34]. Women with very short birth intervals experienced anaemia, gestational diabetics and high-blood pressure which contributed increased risks of premature or low birthweight babies. This study also explored that short birth intervals of less than 18 months contributed to multiple health complications during pregnancy, and thus had significant effect on high-risk pregnancies. In addition to this, maternal health complications could occur due to the adverse biological effects of high parity and short birth intervals. Generally, in high order births (more than three) women experience multiple and life-threatening complications. Grand multiparous women are older and less likely to have accessed antenatal care, which results in an increased risk of maternal complications and poor neonatal outcomes $[16,18,35]$. The results also showed a significant relationship between high-risk pregnancies and maternal healthcare utilisation. Only one-half of women in the study had received sufficient antenatal care during pregnancy. Women who received sufficient antenatal care and who received treatment for health complications were more likely to experience sound pregnancy health and reduced chances of high-risk pregnancies.

\section{Conclusion}

The main focus of this research was to investigate the associations between women's autonomy and high-risk pregnancy, and as discussed above, all three indicators of autonomy appeared to have significant effects on highrisk pregnancy (Model 1). However, once the effects of childbearing practices and antenatal care were accounted for, the effects of autonomy in physical mobility became insignificant. This phenomenon indicates that women's freedom of movement influences high-risk pregnancies through maternal age, parity, birth interval as well as uptake of antenatal care. Thus, both childbearing practices and antenatal care mediate the association between maternal autonomy in physical mobility and high-risk pregnancies. In other words, the effects of autonomy are mediate only in a limited way through the mediating factors. To reduce the prevalence of high-risk pregnancies in Bangladesh, attention needs to be given to increase the level of autonomy of women, in particular their autonomy in decision making and economic matters. It is equally important to pay attention to women's age at birth, number of children, intervals between births and access to antenatal care services so as to improve mothers' reproductive health and pregnancy outcomes for both mother and child.

\section{Abbreviations}

ANC: Antenatal care; BDHS: Bangladesh Demographic and Health Survey; WHO: World Health Organization

\section{Acknowledgements \\ We would like to thank MEASURE DHS for providing us with the nationally representative dataset. We would also like to extend our thanks to the participants of the BDHS 2011.}

\section{Authors' contributions}

SA and DA contributed to the conceptualization and planning of this study. SA performed the statistical analyses and drafted the manuscript. DA revised and edited the final version of this manuscript. Both the authors read and approved the submission.

\section{Funding}

The authors have no support or funding to report for the present study.

\section{Availability of data and materials}

The dataset generated and analysed for the present study is freely available at http://dhsprogram.com/data/

Ethics approval and consent to participate

We obtained permission from the MEASURE DHS to download and analyse the 2011 BDHS data-set for our study purpose. The data were originally collected by the Macro, Calverton, USA. The 2011 BDHS data collection procedures were approved by the ORC Macro-institutional review board. The protocol of the survey was reviewed and approved by the National Ethics Review Committee of the Bangladesh Ministry of Health and Family Welfare.

Consent for publication

Not applicable for this study.

Competing interests

None of the authors have any competing interests. 


\section{Author details}

'Department of Population Science, University of Rajshahi, Rajshahi, Bangladesh. ${ }^{2}$ School of Social Sciences, Monash University, Melbourne, Australia.

Received: 24 September 2019 Accepted: 15 September 2020 Published online: 22 September 2020

\section{References}

1. Davis K and J. Blake 1956. "Social structure and fertility: An analytic framework". Econ Dev Cultural Change. 4: 211-235.

2. Gilbert ES. 2010. Manual of High Risk Pregnancy and Delivery. MO: Mosby.

3. Enkin M, et al. A Guide to Effective Care in Pregnancy and Childbirth. Oxford: Oxford University Press; 2000.

4. Kabeer N. Between affiliation and autonomy: navigating pathways of women's empowerment and gender justice in rural Bangladesh. Dev Change. 2011;42(2):499-528.

5. Rahman MM and S. Abedin. Factors affecting neonatal mortality in Bangladesh. Journal of Health Management. 2010;12(2):137-52.

6. Salihu HM, et al. Perinatal mortality associated with abruption placenta in singletons and multiples. American Journal of Obstetrics Gynaecology. 2005; 193(1):198-203.

7. Savitz DA, et al. Poverty, education, race, and pregnancy outcome. Ethnicity Disease. 2004;14(3):322-9.

8. Choudhury $\mathrm{N}$, et al. Beliefs and practices during pregnancy and childbirth in urban slums of Dhaka, Bangladesh. BMC Public Health. 2012;12(1):791.

9. Mumtaz Z and S. Salway. 'I never go anywhere': extricating the links between women's mobility and uptake of reproductive health services in Pakistan. Soc Sci Med. 2005;60(8):1751-65.

10. Sayem A, Nury AT. Factors associated with teenage marital pregnancy among Bangladeshi women. Reproductive Health. 2011;8(1):16.

11. Liou JD, Hsu JJ, Lo LM, Chen SF, and TH Hung. Advanced maternal age and adverse perinatal outcomes in an Asian population. European Journal of Obstetrics \&Gynaecology Reproductive Biology. 2010;148(1):21-6.

12. Muganyizi PS, Kidanto HL. Impact of change in maternal age composition on the incidence of Caesarean section and low birth weight: analysis of delivery records at a tertiary hospital in Tanzania, 1999-2005. BMC Pregnancy Childbirth. 2009;9(1):30.

13. Luke B, Brown MB. Elevated risks of pregnancy complications and adverse outcomes with increasing maternal age. Hum Reprod. 2007;22(5):1264-72.

14. Cunnington AJ. "What's so bad about teenage pregnancy?". Journal of Family Planning Reproductive Health Care. 2001;27(1):36-41.

15. Gausia K, et al. Obstetric complications and psychological well-being: experiences of Bangladeshi women during pregnancy and childbirth. Journal of Health Population Nutrition. 2012;30(2):172.

16. Khan R, et al. An Examination of Women Experiencing Obstetric Complications Requiring Emergency Care: Perceptions and Socio-cultural Consequences of Caesarean Sections in Bangladesh. Journal of Health Population Nutrition. 2012;30(2):159.

17. Sikder SS, et al. Accounts of severe acute obstetric complications in Rural Bangladesh. BMC Pregnancy Childbirth. 2011;11(1):76.

18. Teguete I, et al. Maternal and neonatal outcomes of grand multiparas over two decades in Mali. Acta Obstetrics gynaecology Scandinavia. 2012;91(5): 580-6.

19. Shaikh K, et al. The association between parity, infant gender, higher level of paternal education and preterm birth in Pakistan: a cohort study. BMC Pregnancy Childbirth. 2011;11(1):88.

20. DaVanzo J, et al. The effects of pregnancy spacing on infant and child mortality in Matlab, Bangladesh: How they vary by the type of pregnancy outcome that began the interval. Population Studies. 2008;62(2):131-54.

21. Royce RA. Birth spacing - the long and short of it. JAMA: The Journal of the American Medical Association. 2006;295(15):1837-8.

22. Conde-Agudelo A, et al. Birth spacing and risk of adverse perinatal outcomes. JAMA: the Journal of the American Medical Association. 2006; 295(15):1809-23.

23. Pervin J, et al. Association of antenatal care with facility delivery and perinatal survival-a population-based study in Bangladesh. BMC Pregnancy Childbirth. 2012;12(1):111.

24. Woldemicael G, Tenkorang EY. Women's autonomy and maternal healthseeking behaviour in Ethiopia. Matern Child Health J. 2010;14(6):988-98.
25. Mistry R, Galal O, M Lu. Women's autonomy and pregnancy care in rural India: A contextual analysis. Soc Sci Med. 2009;69(6):926-33.

26. Mumtaz Z and S. Salway. Gender, pregnancy and the uptake of antenatal care services in Pakistan. Sociol Health IIIn. 2007;29(1):1-26.

27. Bloom SS, et al. Dimensions of women's autonomy and the influence on maternal health care utilization in a north Indian city. Demography. 2001; 38(1):67-78.

28. National Institute of Population Research and Training (NIPORT). Bangladesh Demographic and Health Survey 2011. Mitra and Associates, ICF International. Dhaka and Rockvill.

29. Razzaque A, et al. Pregnancy spacing and maternal morbidity in Matlab, Bangladesh. International Journal of Gynaecology\& Obstetrics. 2005;89:41-9.

30. Singh S, Darroch JE. Adolescent pregnancy and childbearing: levels and trends in developed countries. Fam Plann Perspect. 2000;32(1):14-23.

31. Kim JM, Labrique L, West KP, M rashid. 2012. "Maternal morbidity in early pregnancy in rural northern Bangladesh". Int J Gynaecol Obstet. 119: 227-33.

32. Lumbiganon $P$, et al. Method of delivery and pregnancy outcomes in Asia: the WHO global survey on maternal and perinatal health 2007-08. The Lancet. 2010;375(9713):490-9.

33. Geidam A, et al. Pregnancy outcome among grand multiparous women at the University of Maiduguri Teaching Hospital: A case control study. Journal of Obstetrics Gynaecology. 2011;31(5):404-8.

34. Rutstein SO. Effects of preceding birth intervals on neonatal, infant and under-five years' mortality and nutritional status in developing countries: evidence from the demographic and health surveys. Int J Gynaecol Obstet. 2005;89(1):7.

35. Islam MA, et al. Complications during pregnancy, delivery, and postnatal stages and place of delivery in rural Bangladesh. Health Care Women Int. 2006;27(9):807-21.

\section{Publisher's Note}

Availability of data

Ready to submit your research? Choose BMC and benefit from:

- fast, convenient online submission

- thorough peer review by experienced researchers in your field

- rapid publication on acceptance

- support for research data, including large and complex data types

- gold Open Access which fosters wider collaboration and increased citations

- maximum visibility for your research: over $100 \mathrm{M}$ website views per year

At BMC, research is always in progress.

Learn more biomedcentral.com/submissions 